\title{
Numerical Investigation on Fracture Initiation Properties of Interface Crack in Dissimilar Steel Welded Joints
}

Longfei Zhao ${ }^{1}$, Chendong Shao ${ }^{1}$, Yasuhito Takashima ${ }^{2}$ Fumiyoshi Minami ${ }^{2^{*}}$ and Fenggui $\mathrm{Lu}^{1,2^{*}}$ (D)

\begin{abstract}
Fracture toughness property is of significant importance when evaluating structural safety. The current research of fracture toughness mainly focused on crack in homogeneous material and experimental results. When the crack is located in a welded joint with high-gradient microstructure and mechanical property distribution, it becomes difficult to evaluate the fracture toughness behavior since the stress distribution may be affected by various factors. In recent years, numerical method has become an ideal approach to reveal the essence and mechanism of fracture toughness behavior. This study focuses on the crack initiation behavior and driving force at different interfaces in dissimilar steel welded joints. The stress and strain fields around the crack tip lying at the interfaces of ductile-ductile, ductile-brittle and brittle-brittle materials are analyzed by the numerical simulation. For the interface of ductile-ductile materials, the strain concentration on the softer material side is responsible for ductile fracture initiation. For the ductile-brittle interface, the shielding effect of the ductile material plays an important role in decreasing the fracture driving force on the brittle material side. In the case of brittle-brittle interface, a careful matching is required, because the strength mismatch decreases the fracture driving force in one side, whereas the driving force in another side is increased. The results are deemed to offer support for the safety assessment of welded structures.
\end{abstract}

Keywords: Dissimilar steel welded joint, Fracture initiation, Interface, Strength mismatch, Numerical simulation

\section{Introduction}

The fracture toughness is one of the most important mechanical properties for welded joints where inhomogeneous microstructure is a potential cause of the incidence of structure failure [1-4]. It is important to probe into the fracture behavior of weldments to ensure the running safety. The fracture behavior of homogeneous materials is a subject of wide interest $[5,6]$. Specific areas in welded joints such as weld center and heat affected zone are carefully examined according to the international standards [7]. Gradient microstructure has been reported near the fusion interface of welded joint, which

\footnotetext{
*Correspondence: minami@jwri.osaka-u.ac.jp; Lfg119@sjtu.edu.cn

1 Shanghai Key Laboratory of Materials Laser Processing and Modification, School of Materials Science and Engineering, Shanghai Jiao Tong University, Shanghai, China

2 Joining and Welding Research Institute, Osaka University, Osaka, Japan
}

may lead to stress concentration and crack formation [8, 9]. In particular, a crack adjacent to the interface between different zones poses a potential threat to the reliability of welded equipment [10]. Thus, it is of great significance to investigate the fracture resistance of interface in welded components.

Interface cracks generally show uncontrollable fracture behavior due to strength mismatch and microstructure discrepancy [11, 12]. Nevertheless, dissimilar metals are often joined together to meet a specific requirement in the service environment in order to make the best use of materials and to save cost [13, 14]. Microstructure in dissimilar steel welded joints are much complicated. Hence, those require considerable attention to interfaces between different metals [15]. Samal et al. [16] found that the crack growth path transited from one material to the other when both base metals joined are ductile. Similar 
finding was reported in the research work of Ogawa et al. [17]. Yang et al. discussed the fracture properties of the interface crack by the numerical calculation of the plastic strain ahead of the crack tip with the $J$-resistance curve $[18,19]$. The matching capability of filler wires for dissimilar steels will determine the fracture toughness of weld metal. The GTN model is popularly applied for the study of the crack growth for ductile materials [20-23]. However, little information is available on the interface fracture between brittle and ductile microstructures in dissimilar steel welded joints.

This study mainly aims at the driving force of fracture initiation at interfaces in dissimilar steel welded joints. A numerical simulation is performed to investigate the stress and strain distributions around the crack tip at the interfaces for ductile-to-ductile, ductile-to-brittle and brittle-to-brittle microstructures. The strength mismatch effect of filler wire on dissimilar steels is discussed. A critical strength mismatching for a ductile-brittle interface crack and a critical Weibull stress for a brittle-brittle interface crack are put forward for guiding welding methods and parameters optimization.

\section{FE Modeling}

A dissimilar steel welded joint contains five regions: BM1, HAZ1, WM, HAZ2 and BM2. The mechanical property and microstructure vary a lot in WM and HAZs where the microstructure is completely inhomogeneous. For convenience, the welded joint in this paper was simplified as an idealized five-material layered structure with rectangular shape, as shown in Figure 1. Additionally, the mechanical properties of each zone were assumed to be homogeneous for the sake of simplicity. The effect of such assumptions and simplifications on the results would be discussed later. In this paper, fracture initiation behaviors at three interfaces were studied. In the actual welded joints of concern, the microstructure on BM1 side and HAZ1 side are bainite and tempered bainite, respectively. These regions hold good fracture toughness, as reported by researchers [24].

Bainite steel (BM1) and martensite steel (BM2) were employed as base metals, and different filler wire was considered according to the design requirement for a steam turbine rotor. Table 1 shows the mechanical

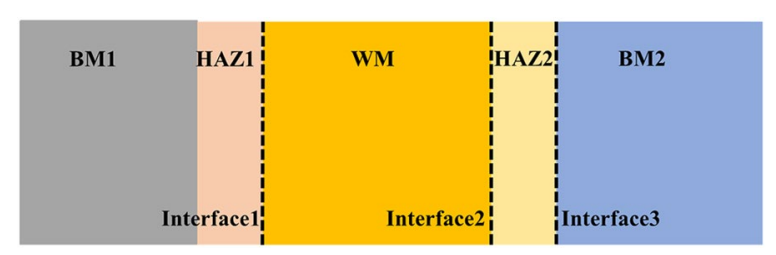

Figure 1 Interfaces in dissimilar steel welded joint
Table 1 Mechanical properties of BMs, WM and HAZs in dissimilar steel joint used for FE-analysis

\begin{tabular}{llll}
\hline Regions & $\begin{array}{l}\text { Yield strength } \\
\boldsymbol{R}_{\mathbf{p 0 . 2}}(\mathbf{M P a})\end{array}$ & $\begin{array}{l}\text { Strain hardening } \\
\text { exponent } \boldsymbol{n}\end{array}$ & $\begin{array}{l}\text { Yield } \\
\text { strength } \\
\text { mismatch } \boldsymbol{M}\end{array}$ \\
\hline $\mathrm{BM1}$ & 510 & 6.6 & - \\
$\mathrm{HAZ1/WM}$ & $610 / 435$ & $9.6 / 10.7$ & 1.40 \\
& $610 / 500$ & $9.6 / 10.7$ & 1.20 \\
& $610 / 635$ & $9.6 / 10.7$ & 0.96 \\
& $610 / 735$ & $9.6 / 10.7$ & 0.80 \\
HAZ2/WM & $850 / 567$ & $10.5 / 10.7$ & 1.50 \\
& $850 / 600$ & $10.5 / 10.7$ & 1.40 \\
& $850 / 635$ & $10.5 / 10.7$ & 1.30 \\
& $850 / 735$ & $10.5 / 10.7$ & 1.20 \\
HAZ2/BM2 & $850 / 650$ & $10.5 / 8.9$ & 1.30 \\
\hline
\end{tabular}

properties of these regions in the dissimilar steel joint for modeling. Yield strengths for different zones in the joint were measured with micro-flat-tensile (MFT) specimens [24]. Those for BM1, BM2, HAZ1, HAZ2 and that of WM were $510 \mathrm{MPa}, 650 \mathrm{MPa}, 610 \mathrm{MPa}, 850 \mathrm{MPa}$ and 635 $\mathrm{MPa}$, respectively. The numerical analysis in this paper employs a simple power-hardening model [25] to characterize the uniaxial true stress-true strain in the form:

$$
\frac{\bar{\varepsilon}}{\varepsilon_{y s}}=\frac{\bar{\sigma}}{\sigma_{y s}}, \bar{\varepsilon} \leq \varepsilon_{y s} ; \frac{\bar{\varepsilon}}{\varepsilon_{y s}}=\left(\frac{\bar{\sigma}}{\sigma_{y s}}\right)^{n}, \quad \bar{\varepsilon}>\varepsilon_{y s},
$$

where $\sigma_{y s}$ and $\varepsilon_{y s}$ denote the yield strength and strain, and $n$ is the strain hardening exponent. It is seen in Table 1 that fixed values of yield strength were used for the BMs and HAZs, while different values were adopted for the WM to study the effect of strength mismatch $(M)$ on the fracture initiation behavior at the HAZ/WM interfaces. The fracture toughness of WM with the yield strength of $635 \mathrm{MPa}$ was informed by the experimental results [24].

Single-edge notched bend (SENB) specimens were used to investigate the fracture toughness of different zones in the welded joint [24]. The SENB specimen had a length of $140 \mathrm{~mm}$, a width $W$ of $30 \mathrm{~mm}$ and a thickness of $15 \mathrm{~mm}$. The initial crack depth ratio of $a_{0} / W$ was 0.5 and the loading span $S$ was $120 \mathrm{~mm}$. The crack locations are shown in Figure 2. The fracture toughness of HAZ1 and HAZ2 was measured with specimens having a notch in HAZ1 and HAZ2 with side groove. The $J_{\text {Ic }}$-values for BM1, HAZ1 and WM were $321.7 \mathrm{~kJ} / \mathrm{m}^{2}, 266.1 \mathrm{~kJ} / \mathrm{m}^{2}$ and $176.2 \mathrm{~kJ} / \mathrm{m}^{2}$, respectively. The $K_{\mathrm{Q}}$-values for HAZ2 and BM2 were $80 \mathrm{MPa} \cdot \mathrm{m}^{0.5}$ and $100 \mathrm{MPa} \cdot \mathrm{m}^{0.5}$, which were evaluated according to ISO 15653. The widths of HAZs (HAZ1 and HAZ2) and WM were set as $2 \mathrm{~mm}$ and $20 \mathrm{~mm}$, respectively, in the light of experimental measurement. 


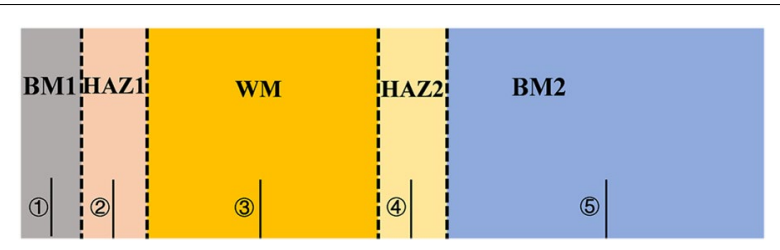

Figure 2 Crack locations in SENB specimens in experiments

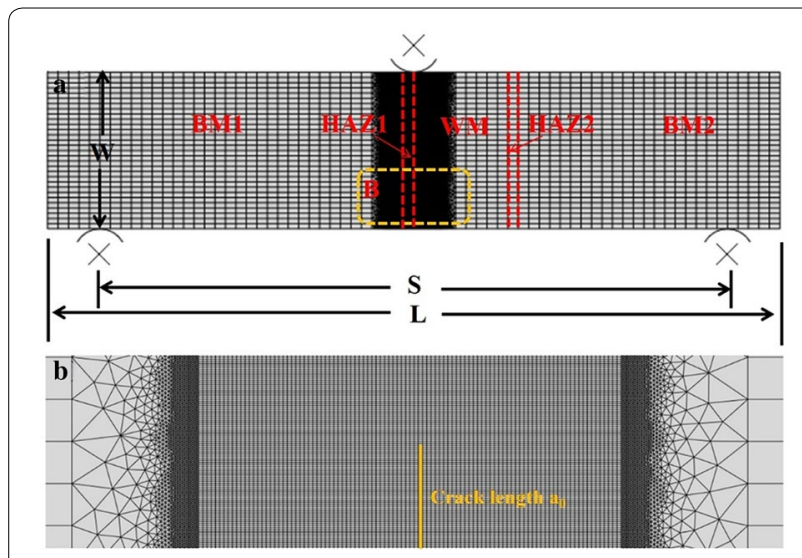

Figure 3 Geometry of SENB specimens and mesh division

In order to warrant simulation accuracy and maximize calculation efficiency simultaneously, a local mesh refinement was implemented in the FE model, as shown in Figure 3. A fine mesh (mesh size: $0.1 \mathrm{~mm} \times 0.05 \mathrm{~mm}$ ) was applied near the crack tip [26], while a relatively larger mesh (mesh size: $2 \mathrm{~mm} \times 1 \mathrm{~mm}$ ) was utilized in the area far away from the crack to improve the calculation efficiency. In the FE model, the 4-node bilinear plane strain quadrilateral elements with reduced integration (CPE4R) and 3-node linear plane strain triangle were selected. The whole FE model contains 94748 elements. The initial crack will be set on the different interfaces.

The stress and strain fields evolution during fracture initiation were calculated by the commercial FE code
ABAQUS/Explicit method. As shown in Figure 3, a surface to surface contact condition was defined between the analytic rigid body and the SENB specimen, the fraction coefficient was set as 0.3. Consistent with the experimental process, the supporting rolls were fixed, and the specimen was loaded by the loading roll through displacement control.

In order to simulate the interface crack propagation, this paper employs the GTN model [20]. Suitable GTN damage parameters are needed for different regions in the welded joint. The GTN model contains nine parameters in general: the constitutive parameters $q_{1}, q_{2}$ and $q_{3}$, the initial void volume fraction $f_{0}$, the void nucleation parameters $f_{\mathrm{N}}, \varepsilon_{\mathrm{N}}$ and $S_{\mathrm{N}}\left(f_{\mathrm{N}}\right.$ : volume fraction of void-forming particles, $\varepsilon_{\mathrm{N}}$ : mean void nucleation strain, and $S_{\mathrm{N}}$ : corresponding standard deviation), the critical void volume fraction $f_{\mathrm{c}}$ and the final failure parameter $f_{\mathrm{F}}$. When the void volume fraction reaches the critical void volume fraction $f_{\mathrm{c}}$, the void interaction starts, and while the void volume fraction reaches the failure void volume fraction $f_{\mathrm{F}}$, fracture occurs. It is indicated [27] that GTN constitutive parameters like $q_{1}=1.5, q_{2}=1$, $q_{3}=q_{1}^{2}=2.25$ are reasonable to investigate the crack propagation for medium-strength steels. For low alloy steels, nucleation parameters, such as $\varepsilon_{\mathrm{N}}=0.3, S_{\mathrm{N}}=0.1$, are commonly adopted in most studies $[28,29]$. The determination of the initial void volume fraction $f_{0}$ and void nucleation parameter $f_{\mathrm{N}}$ is generally based on the metallographic and fracture morphology analyses. The parameters $f_{\mathrm{c}}$ and $f_{\mathrm{F}}$ are verified by fitting the numerical results of resistance curves with experimental results.

Table 2 shows a set of GTN parameters employed in various regions, all of which have been validated by toughness tests and tensile tests, confirming their feasibility and reliability in the previous study [24].

In this study, the Weibull stress $\left(\sigma_{\mathrm{W}}\right)$ was employed as the driving force for brittle fracture. The Weibull stress is given by integrating a near-tip stress $\left(\sigma_{\text {eff }}\right)$ over the fracture process zone $\left(V_{\mathrm{f}}\right)$ in the form $[30,31]$ :

Table 2 GTN parameters of BM, HAZ and WM regions in dissimilarly welded joint

\begin{tabular}{llllll}
\hline Region & $\boldsymbol{q}_{\mathbf{1}}$ & $\boldsymbol{q}_{\mathbf{2}}$ & $\boldsymbol{q}_{\mathbf{3}}$ & $\boldsymbol{\varepsilon}_{\mathbf{N}}$ & $\boldsymbol{S}_{\mathbf{N}}$ \\
\hline BM1 & 1.5 & 1.0 & 2.25 & 0.3 & 0.1 \\
HAZ1 & 1.5 & 1.0 & 2.25 & 0.3 & 0.3 \\
WM & 1.5 & 1.0 & 2.25 & $\boldsymbol{f}_{\mathbf{0}}$ & 0.1 \\
\hline Region & $\boldsymbol{f}_{\mathbf{N}}$ & $\boldsymbol{f}_{\mathbf{c}}$ & $\boldsymbol{f}_{\mathbf{F}}$ & 0.001 \\
\hline BM1 & 0.060 & 0.030 & 0.450 & 0.001 \\
HAZ1 & 0.055 & 0.035 & 0.465 & 0.001 \\
WM & 0.082 & 0.018 & 0.263 & & \\
\hline
\end{tabular}




$$
\sigma_{\mathrm{W}}=\left[\frac{1}{V_{0}} \int_{V_{\mathrm{f}}}\left(\sigma_{\mathrm{eff}}\right)^{m} \mathrm{~d} V_{\mathrm{f}}\right]^{1 / m}
$$

where $V_{\mathrm{f}}$ is the volume of the near-tip fracture process zone (FPZ) which is most often defined as the region where $\sigma_{1} \geq \lambda \sigma_{y s}\left(\sigma_{1}\right.$ : maximum principal stress, $\sigma_{y s}$ : yield strength and $\lambda \geq 1)$. In this work, $\sigma_{\text {eff }}=\sigma_{1}$ and $\lambda=1$ were adopted. For the interface crack, the process zone was confined in the material on one side of the crack, and the Weibull stress was calculated on each side of the crack. The reference volume $V_{0}$ has no effect on the shape parameter $m$ and is assigned as a unit value $\left(V_{0}=1 \mathrm{~mm}^{3}\right)$ in the computation for convenience. The Weibull parameter of $m=20$ was selected.

\section{Numerical Results}

\subsection{Fracture Initiation Behavior at Interface of Ductile Materials}

The FE-analysis was carried out on the stress/strain distribution and crack initiation for the crack lying at the HAZ1/WM interface. The yield strength mismatch $(M)$ between HAZ1 and WM was ranged as 1.4, 1.2, 0.96 and 0.8 . The mismatch of the weld in an actual turbine rotor was about 0.96 with the yield strengths of HAZ1 and WM of $610 \mathrm{MPa}$ and $635 \mathrm{MPa}$, respectively [24].

Figure 4 presents the distributions of strain and stress around crack tip at the interface between HAZ1/WM. It is found that the stress-strain fields near the crack tip for $M<1$ and those for $M \geq 1.2$ are totally different. Figure $4 \mathrm{a}, \mathrm{c}$, e and g indicate that equivalent plastic strain concentrates dominantly on the side with lower yield strength. For ductile-ductile interfaces, the initiation of crack always occurs on the lower strength material side, as shown in Figure 4b, d, f, and h.

Figure 5 shows the strain distributions for SENB with HAZ1 of $2 \mathrm{~mm}$ width and $20 \mathrm{~mm}$ width under the mismatch condition of $M=0.96$. Although nearly match condition, asymmetric plastic deformation occurs, which is due to the adjacent BM1 with much lower yield strength. Namely global mismatch controls the asymmetric plastic deformation near the interface. On the other hand, in the cases of $M=1.4$ and 1.2 (Figure $4 \mathrm{a}$ and c), the local mismatch between HAZ1 and WM1 is responsible for the asymmetric strain distribution.

\subsection{Fracture Initiation Behavior at Interface of Ductile and Brittle Materials}

For SENB with a crack at the interface between WM and HAZ2, the strength mismatch exerts a great influence on the stress/strain distribution around the crack tip. The strength mismatch between HAZ2 and WM was ranged from $M=1.2-1.5$. Figure 6 shows the distribution of strain and stress at the crack tip when the peak

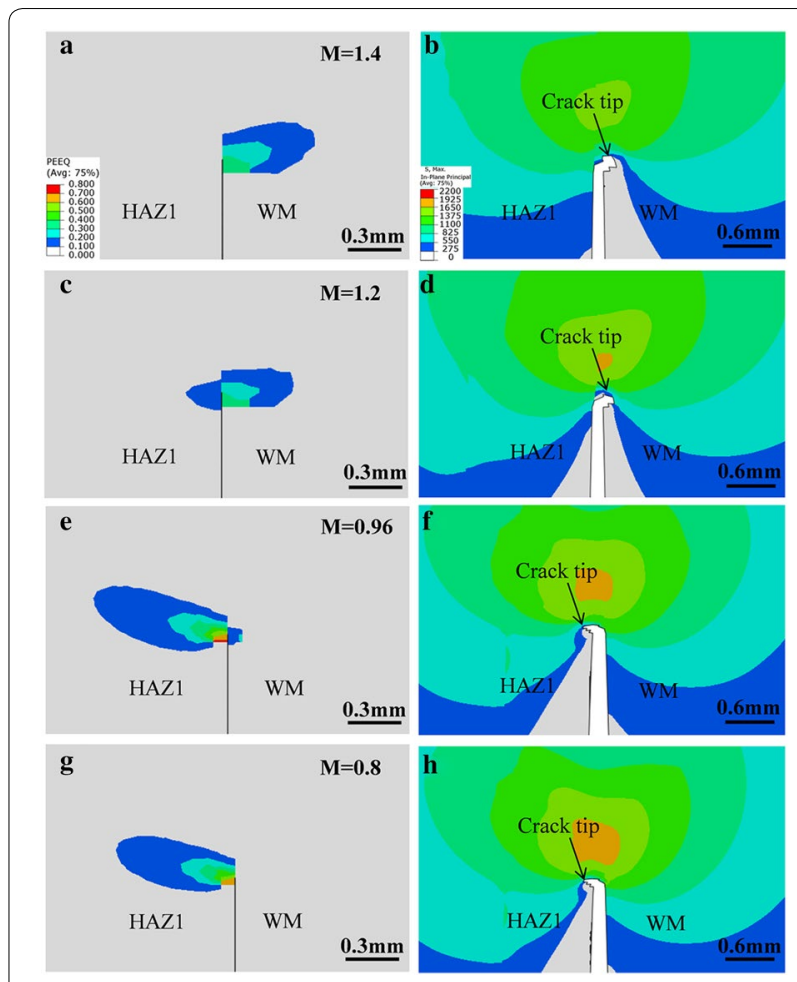

Figure 4 Distributions of strain and stress around crack tip at the interface between HAZ1/WM: a, c, e, $\mathbf{g}$ Equivalent plastic strain (PEEQ); (b)(d)(f)(h) Maximum principal stress (S, max). (Unit in $\mathbf{b}, \mathbf{d}, \mathbf{f}$, $\mathbf{h}$ is $\mathrm{MPa}$ )

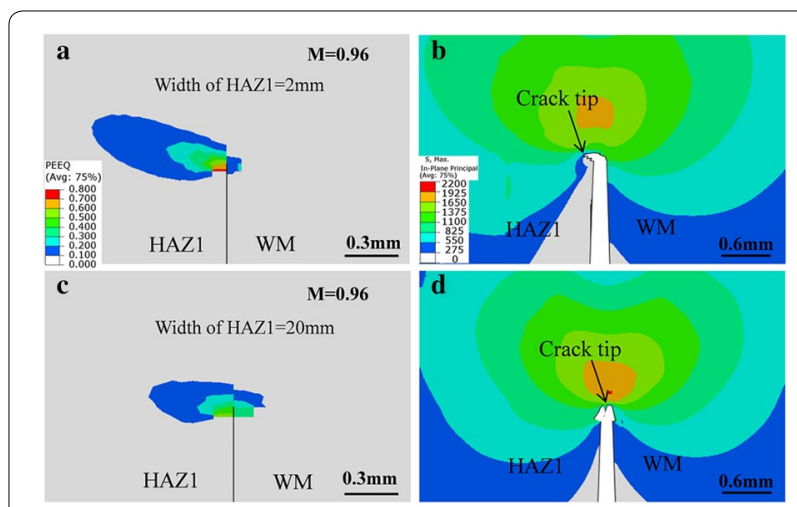

Figure 5 Distributions of strain and stress around crack tip for SENB with different HAZ widths: $\mathbf{a}, \mathbf{b}$ HAZ1 width $=2 \mathrm{~mm}$; c, d HAZ1 width $=20 \mathrm{~mm}$ (Unit in $\mathbf{b}$, $\mathbf{d}$ is $\mathrm{MPa}$ )

value of the maximum principle stress is reached during the load. As indicated in Figures 6a, c and e, the plastic strain at the crack tip concentrates on the weld metal side when the mismatch is higher than 1.3. Figure $6 \mathrm{~b}, \mathrm{~d}$ and $\mathrm{f}$ prove that the maximum principal stress at the crack tip was lower than the critical failure stress of $2300 \mathrm{MPa}$ for HAZ2, which indicates no brittle fracture in HAZ2. 


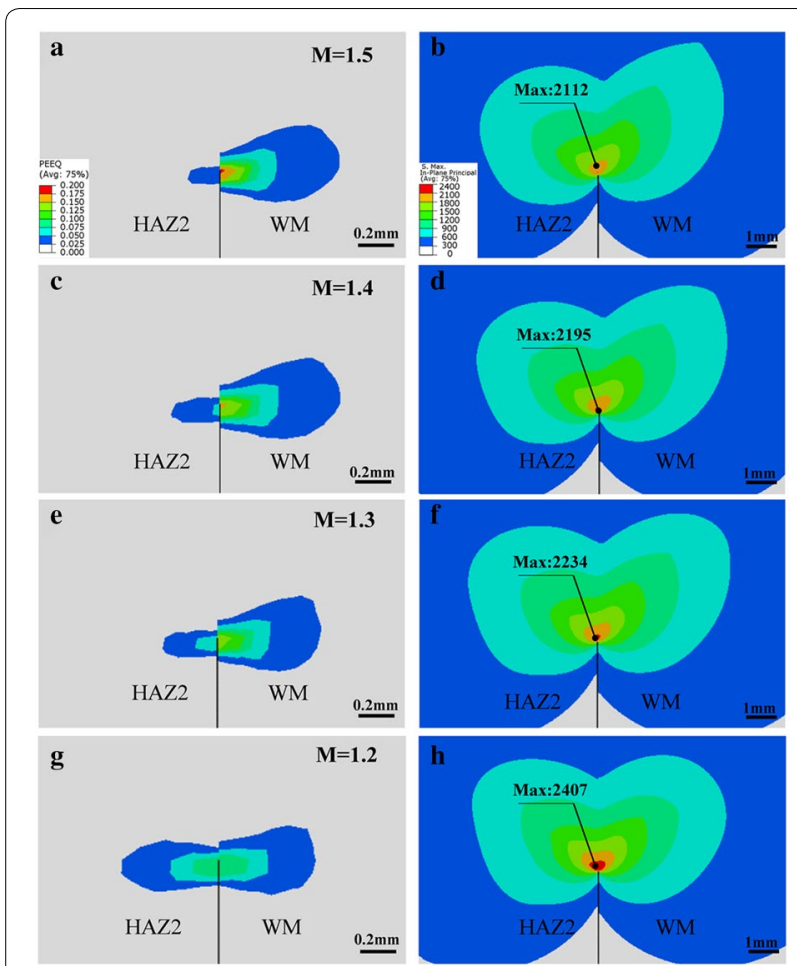

Figure 6 Distributions of strain and stress around crack tip at the interface between HAZ2/WM: $\mathbf{a}, \mathbf{c}, \mathbf{e}, \mathbf{g}$ Equivalent plastic strain (PEEQ); $\mathbf{b}, \mathbf{d}, \mathbf{f}, \mathbf{h}$ Maximum principal stress (S, max) (Unit in $\mathbf{b}, \mathbf{d}, \mathbf{f}, \mathbf{h}$ is $\mathrm{MPa}$ )

However, under the mismatch condition of $M=1.2$, the strain field near the crack tip develops on both weld metal and HAZ2 sides, as shown in Figure 6g. The maximum principal stress at the crack tip reaches the critical failure stress of HAZ2 as shown in Figure 6h.

The Weibull stress and cavity volume fraction were applied as the critical parameters for crack initiation of HAZ2 (brittle side) and WM (ductile side) in this paper. Figure 7 describes the relationship between the Weibull stress and stress intensity factor for HAZ2 (SENB specimen with crack in HAZ2 and side groove). The $K_{\mathrm{Q}^{-}}$ value for HAZ2 measured was $80 \mathrm{MPa} \cdot \mathrm{m}^{0.5}$. The critical Weibull stress for $\mathrm{HAZ2}$ at $K_{\mathrm{Q}}=80 \mathrm{MPa} \cdot \mathrm{m}^{0.5}$ is about $2300 \mathrm{MPa}$, as shown in Figure 7.

Figure 8 displays the development of the Weibull stress in HAZ2 region and the cavity volume fraction in WM region with stress intensity factor $(K)$. It can be seen that for mismatch of $M=1.3,1.4,1.5$, the Weibull stress in HAZ2 cannot exceed $2300 \mathrm{MPa}$ as exhibited in Figure 8a. Therefore, the brittle crack does not initiate in HAZ2 under the mismatch ratio $M=1.3,1.4,1.5$. At the mismatch of $M=1.2$, the Weibull stress easily reaches the critical value of $2300 \mathrm{MPa}$ before the cavity volume fraction in WM increases dramatically, as shown in

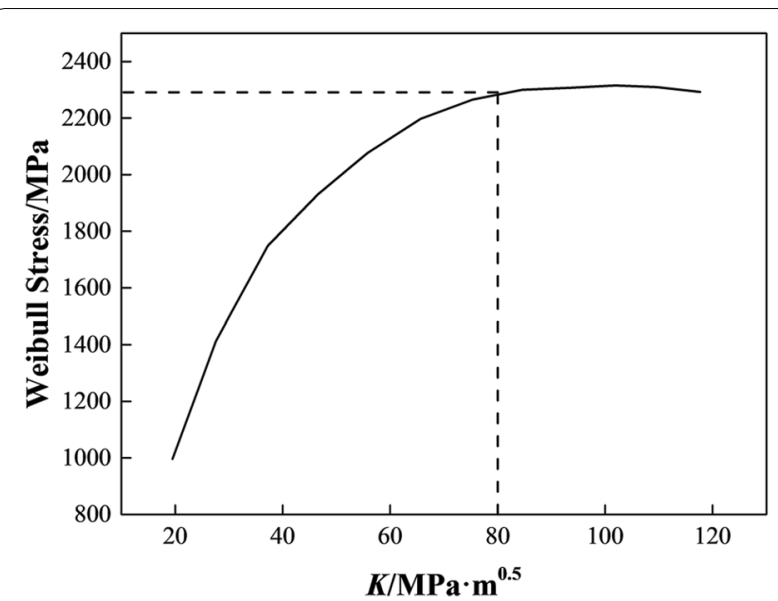

Figure 7 Relationship between Weibull stress and stress intensity factor of HAZ2

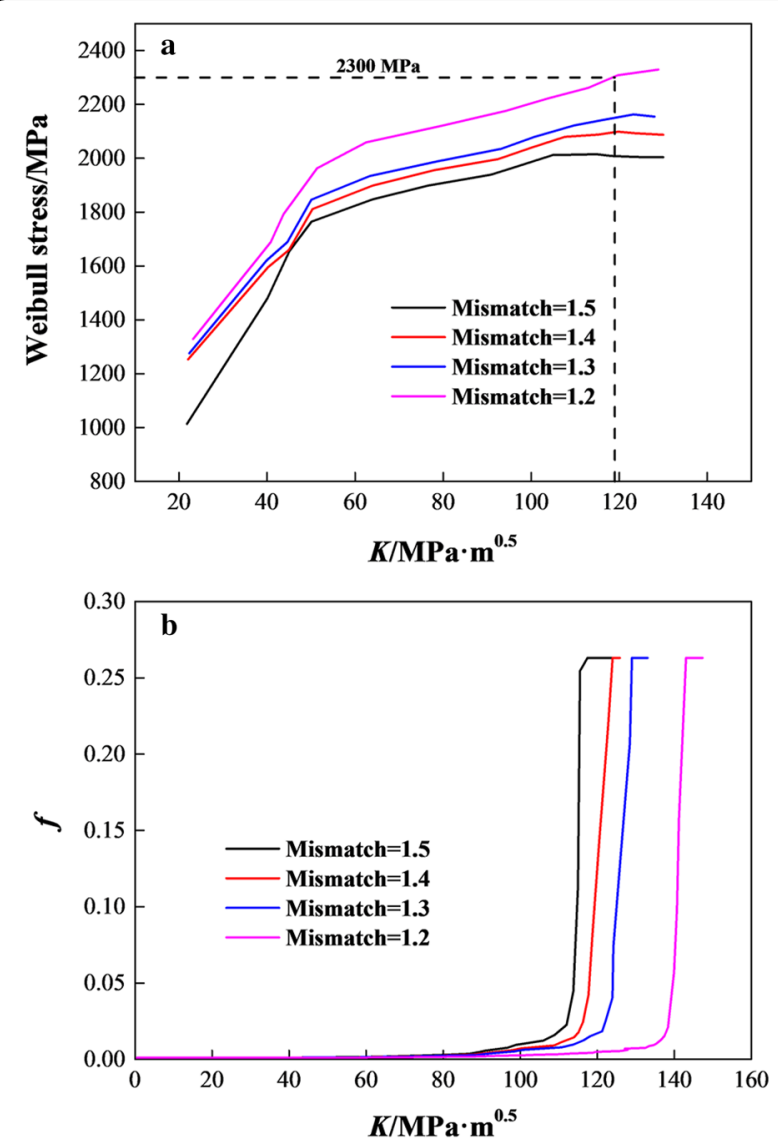

Figure 8 Development of Weibull stress in HAZ2 and cavity volume fraction (f) in WM for crack at WM/HAZ2 interface: a Weibull stress in HAZ2; b Cavity volume fraction in WM 
Figure $8 \mathrm{~b}$, leading to the brittle crack initiation in HAZ2. Hence, a conclusion can be drawn that a shielding effect provided by the ductile WM is expected for the interface crack when $M>1.2$. The mismatch condition of $M \leq 1.2$ will result in the occurrence of brittle failure in HAZ2.

Figure 9 shows the effect of HAZ2 width on the Weibull stress in HAZ2 for the crack at WM/HAZ2 interface under the mismatch of $M=1.2$. The Weibull stress in HAZ2 decreases with decreasing the HAZ2 width. This is partly due to the volume effect of HAZ2. Another reason is found for the change of the stress intensity with the HAZ2 width. The crack opening stress at the crack tip in $\mathrm{x}$ axis direction and $\mathrm{y}$ axis direction is reduced as shown in Figure 10. The Weibull stress for HAZ2 is decreased with decreasing the width of HAZ2. In order to avoid the failure in the brittle HAZ2, the HAZ2 width should be as narrow as possible.

\subsection{Fracture Initiation Behavior at the Interface of Brittle Materials}

Fracture initiation behaviors of the dissimilar joint with a crack at brittle materials are investigated with FE-models shown in Figure 11. Three crack locations are considered: Crack in HAZ2, crack in the homogeneous BM2 and crack at the interface of BM2 and HAZ2 (in this case, $M=1.3)$. The cracks in HAZ2 and in BM2 simulated the actual specimens used in the experiments. Figure 12 describes the relationship between the Weibull stress and stress intensity factor for these models. The fracture process zones are exhibited in Figure 11, for the interface crack the fracture process zones on HAZ2 side and BM2 side were distinguished as shown in Figure 11c. The $K_{\mathrm{Q}}$-values measured with the SENB specimens were 100 $\mathrm{MPa} \cdot \mathrm{m}^{0.5}$ and $80 \mathrm{MPa} \cdot \mathrm{m}^{0.5}$ for BM2 and HAZ2, respectively, which resulted in the critical Weibull stresses of

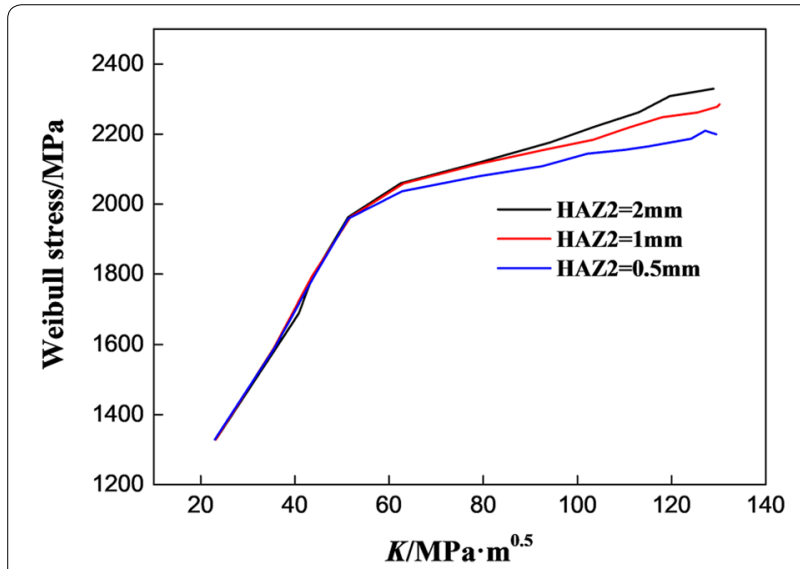

Figure 9 Effect of HAZ2 width on Weibull stress in HAZ2 under mismatch of $M=1.2$
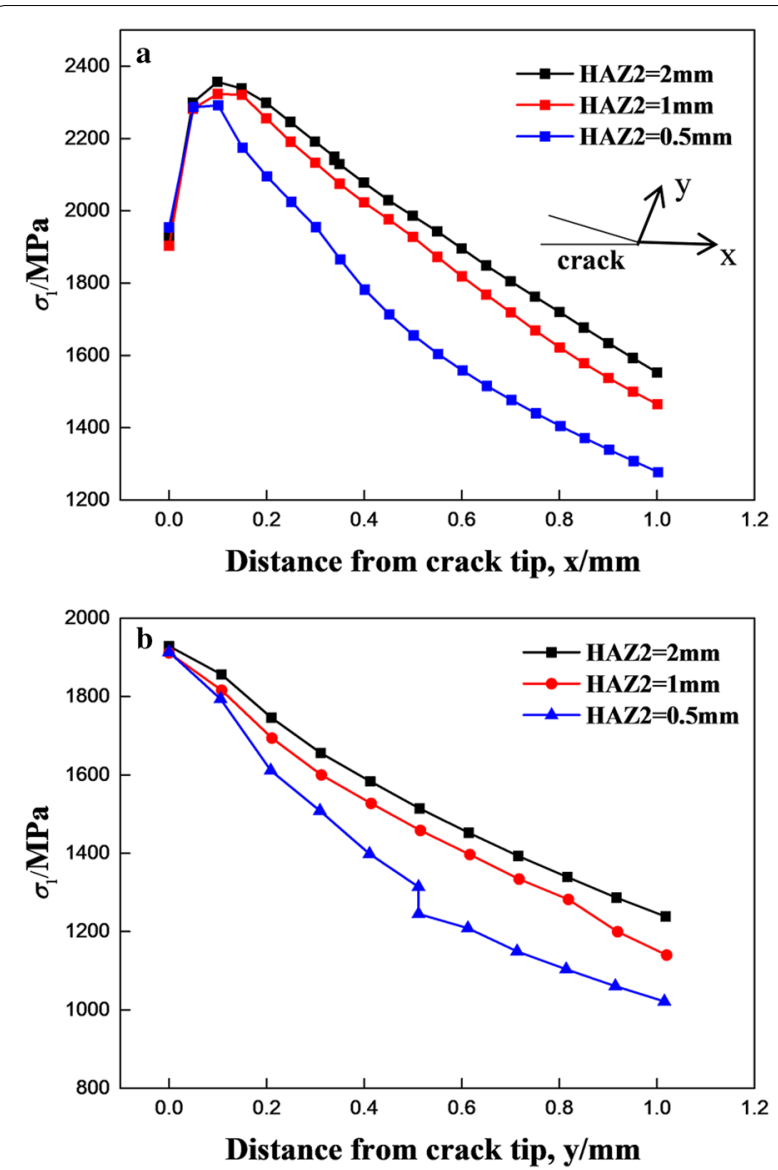

Figure 10 Effect of HAZ2 width on crack opening stress ahead of crack tip under $M=1.2$ at $K=120 \mathrm{MPa} \cdot \mathrm{m}^{0.5}$ : a Stress distribution in $x$-axis direction; $\mathbf{b}$ Stress distribution in $y$-axis direction
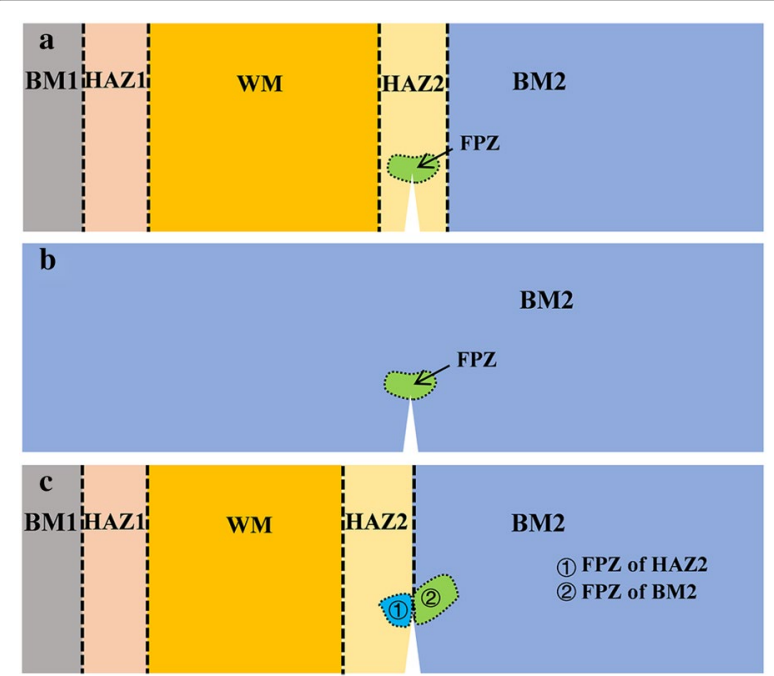

Figure 11 Crack location in SENB specimen: a Crack in HAZ2; b Crack in BM2; c Crack at BM2/HAZ2 interface 


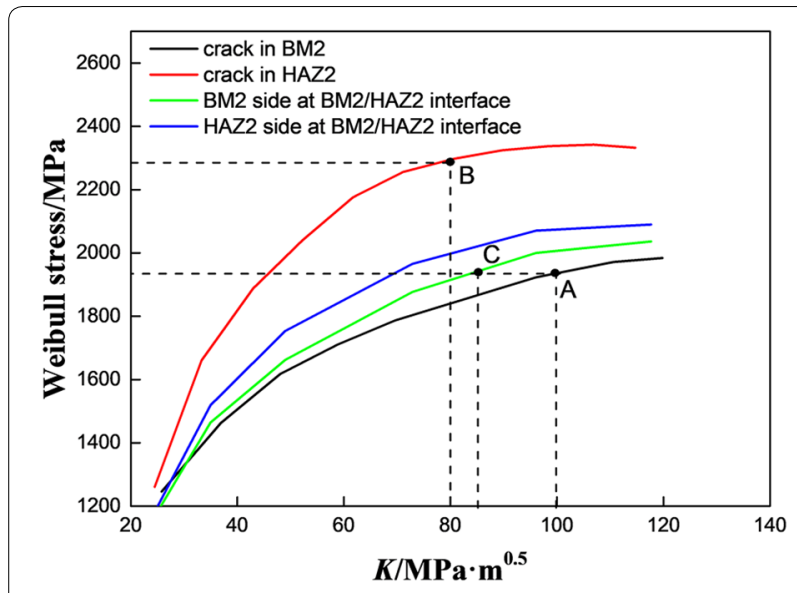

Figure 12 Relationship between Weibull stress and stress intensity factor for brittle interface crack

$1930 \mathrm{MPa}$ and $2300 \mathrm{MPa}$ for BM2 and HAZ2, as exhibited by points $A$ and $B$. It can be seen that Weibull stress on HAZ2 side at the interface does not attain to the critical value of $2300 \mathrm{MPa}$ for pure HAZ2. In contrast, the Weibull stress on BM2 side at interface reaches 1930 $\mathrm{MPa}$ (critical value for BM2) at the point $\mathrm{C}$ as labeled in Figure 11. These results indicate the importance of a reasonable matching of BM and HAZ for the integrity of dissimilar welded joints.

\section{Discussion}

The fracture toughness as well as strength matching in dissimilar steel welded joints plays a significant role in determining the service life of welded components. In the actual dissimilar steel welded joint, the interface between WM and HAZ is often a ductile-brittle interface. Embrittlement in HAZ is due to the existence of the coarse grain zone near the fusion line. Choosing different wires as filling metal could control the fracture sensitivity of the brittle HAZ. The numerical results in Section $3.2 \mathrm{dem}-$ onstrate that the brittle fracture initiation in HAZ can be escaped by the selection of low strength WM (mismatch ratio $M>1.2$ ), which leads to the ductile crack initiates on the ductile WM side.

In the case of the brittle-brittle interface, a careful matching is required. The strength mismatch decreases the fracture driving force in one side (constraint loss), whereas the driving force in another side is increased (constraint elevation), as demonstrated by Figure 12.

In the real joint, the fusion lines are always tortuous, which is complicated for modeling. Previously in Figure 1, the WM and HAZ were simplified as rectangular boundary to obtain quadrilateral meshes. Generally, the different shape of the interface would inevitably affect the stress and strain fields distribution near the crack. However, the effect tendency of different materials on the crack initiation behavior was deemed to little influenced. Additionally, such simplification would enhance the numerical convergence and make the results more conservative and safer.

\section{Conclusions}

In this paper, the numerical simulation has investigated the fracture initiation behavior at interfaces in dissimilar steel welded joints. The main conclusions are drawn as follows:

(1) For the interface crack between ductile materials, the ductile fracture originates from a softer material owing to the strain concentration. The local mismatching at the interface mostly controls the asymmetric plastic deformation at the crack tip. However, the global mismatching also takes part in the asymmetric plastic deformation when the local condition at the interface is nearly even.

(2) For ductile-brittle interface, the Weibull stress can be employed as the fracture driving force on the brittle material side. The fracture initiation in brittle HAZ can be escaped by the selection of low strength WM, which leads to the ductile crack initiates on the ductile WM side. This is attributed to a shielding effect of the ductile WM. The shielding effect is promoted by the decrease in the HAZ width.

(3) In the case of brittle-brittle interface, a careful matching is required. The strength mismatch decreases the fracture driving force in one side, whereas the driving force in another side is increased.

\section{Acknowledgments}

Not applicable.

\section{Authors' Contributions}

LZ took most of the research work, including the literature research, modeling, results analysis and paper writing. CS assisted with the results analysis, paper revision and online submitting. YT provided technical supporting for modeling. FM and FL are supervisors who provided opportunity for the cooperative research and offered the original idea for the paper. All authors read and approved the final manuscript.

\section{Authors' Information}

Longfei Zhao, born in 1993, is currently a master candidate at School of Materials Science and Engineering, Shanghai Jiao Tong University, China.

Chendong Shao, born in 1993, is currently a PhD candidate at School of Materials Science and Engineering, Shanghai Jiao Tong University, China.

Yasuhito Takashima, born in 1979, is currently an assistant professor at Joining and Welding Research Institute, Osaka University, Japan.

Fumiyoshi Minami, born in 1954, is currently a professor at Joining and Welding Research Institute, Osaka University, Japan. 
Fenggui Lu, born in 1975, is currently a professor and a PhD candidate supervisor at School of Materials Science and Engineering, Shanghai Jiao Tong University, China.

\section{Funding}

Supported by National Natural Science Foundation of China (Grant Nos. 51675336, U1660101).

\section{Competing Interests}

The authors declare that they have no competing financial interests.

Received: 28 July 2019 Revised: 9 January 2020 Accepted: 13 March 2020 Published online: 31 March 2020

\section{References}

[1] Y Liu, H Cui, F Lu, et al. Research on the fracture toughness of micro zone in the joint based on multi-layer and multi-pass welding of rotor steel. Transactions of the China Welding Institution, 2018, 39 (9): 105-108.

[2] WYu, M Fan, J Shi, et al. A comparison between fracture toughness at different locations of SMAW and GTAW welded joints of primary coolant piping. Engineering Fracture Mechanics, 2018, 202: 135-146.

[3] M Pouranvari. Fracture toughness of martensitic stainless steel resistance spot welds. Materials Science and Engineering a-Structural Materials Properties Microstructure and Processing, 2017, 680: 97-107.

[4] Y Takashima, Y Ito, F Lu, et al. Fracture toughness evaluation for dissimilar steel joints by Charpy impact test. Welding in the World, 2019, 63(5): 1243-1254.

[5] M Braun, J Fernandez-Saez. A new 2D discrete model applied to dynamic crack propagation in brittle materials. International Journal of Solids and Structures, 2014, 51(21-22): 3787-3797.

[6] T Zhang, S Lin, H Yuk, et al. Predicting fracture energies and crack-tip fields of soft tough materials. Extreme Mechanics Letters, 2015, 4: 1-8.

[7] ISO 15653:2018 Metallic materials - Method of test for the determination of quasistatic fracture toughness of welds: International Organization for Standardization, 2018.

[8] YWang, H Cui, M Fan, et al. Characterization on the gradient microstructure near the fusion interface of dissimilar metal between high $\mathrm{Cr}$ heatresistant steel and Ni-based Alloy 617. Materials Characterization, 2019, 151: 227-236.

[9] J Akram, P R Kalvala, P Chalavadi, et al. Dissimilar metal weld joints of P91/ Ni alloy: Microstructural characterization of HAZ of P91 and stress analysis at the weld interfaces. Journal of Materials Engineering and Performance, 2018, 27 (8): 4115-4128.

[10] K Fan, G Z Wang, F Z Xuan, et al. Local fracture resistance behavior of interface regions in a dissimilar metal welded joint. Engineering Fracture Mechanics, 2015, 136: 279-291.

[11] K Fan, G Z Wang, S T Tu, et al. Geometry and material constraint effects on fracture resistance behavior of bi-material interfaces. International Journal of Fracture, 2016, 201(2): 143-155.

[12] K Fan, G Z Wang, F Z Xuan, et al. Correlation of material constraint with fracture toughness of interface regions in a dissimilar metal welded joint. Fatigue \& Fracture of Engineering Materials \& Structures, 2016, 39(10): 1251-1262.

[13] C Shao, F Lu, Z Li, et al. Role of stress in the high cycle fatigue behavior of advanced $9 \mathrm{Cr} / \mathrm{CrMoV}$ dissimilarly welded joint. Journal of Materials Research, 2016, 31(02): 292-301.

[14] K Ding, P Wang, X Liu, et al. Formation of lamellar carbides in alloy 617$\mathrm{HAZ}$ and their role in the impact toughness of alloy $617 / 9 \% \mathrm{Cr}$ dissimilar welded joint. Journal of Materials Engineering and Performance, 2018, 27(11): 6027-6039.

[15] D W Rathod, S Pandey, P K Singh, et al. Microstructure-dependent fracture toughness $(\mathrm{J}(\mathrm{IC}))$ variations in dissimilar pipe welds for pressure vessel system of nuclear plants. Journal of Nuclear Materials, 2017, 493: 412-425.
[16] M K Samal, M Seidenfuss, E Roos, et al. Investigation of failure behavior of ferritic-austenitic type of dissimilar steel welded joints. Engineering Failure Analysis, 2011, 18(3): 999-1008.

[17] T Ogawa, M Itatani, T Saito, et al. Fracture assessment for a dissimilar metal weld of low alloy steel and Ni-base alloy. International Journal of Pressure Vessels and Piping, 2012, 90-91: 61-68.

[18] J Yang, G Z Wang, F Z Xuan, et al. Unified correlation of in-plane and outof-plane constraint with fracture resistance of a dissimilar metal welded joint. Engineering Fracture Mechanics, 2014, 115: 296-307.

[19] J Yang, G Z Wang, F Z Xuan, et al. Out-of-plane constraint effect on local fracture resistance of a dissimilar metal welded joint. Materials \& Design, 2014, 55: 542-550.

[20] A L Gurson. Continuum theory of ductile rupture by void nucleation and growth. I. Yield criteria and flow rules for porous ductile media. Transactions of the ASME. Series H, Journal of Engineering Materials and Technology, 1977, 99(1): 2-15.

[21] S Gatea, H Ou, B Lu, et al. Modelling of ductile fracture in single point incremental forming using a modified GTN model. Engineering Fracture Mechanics, 2017, 186: 59-79.

[22] Y-R Oh, H-S Nam, Y-J Kim, et al. Application of the GTN model to ductile crack growth simulation in through-wall cracked pipes. International Journal of Pressure Vessels and Piping, 2018, 159: 35-44.

[23] Y Zhang, E Lorentz, J Besson. Ductile damage modelling with locking-free regularised GTN model. International Journal for Numerical Methods in Engineering, 2018, 113 (13): 1871-1903.

[24] Q Guo, F Lu, H Cui, et al. Modelling the crack propagation behavior in 9Cr/CrMoV welds. Journal of Materials Processing Technology, 2015, 226: 125-133.

[25] E Wang, W De Waele, S Hertele. A complementary eta(pl) approach in J and CTOD estimations for clamped SENT specimens. Engineering Fracture Mechanics, 2015, 147: 36-54

[26] E Ostby, CThaulow, Z L Zhang. Numerical simulations of specimen size and mismatch effects in ductile crack growth - Part II: Near-tip stress fields. Engineering Fracture Mechanics, 2007, 74(11): 1793-1809.

[27] X S Gao, J Faleskog, C F Shih. Cell model for nonlinear fracture analysis - II. Fracture-process calibration and verification. International Journal of Fracture, 1998, 89(4): 375-398.

[28] N Benseddiq, A Imad. A ductile fracture analysis using a local damage model. International Journal of Pressure Vessels and Piping, 2008, 85(4): 219-227.

[29] A Kami, B M Dariani, A S Vanini, et al. Numerical determination of the forming limit curves of anisotropic sheet metals using GTN damage model. Journal of Materials Processing Technology, 2015, 216: 472-483.

[30] F Minami, A Bruckner-Foit, D Munz, et al. Estimation procedure for the Weibull parameters used in the local approach. International Journal of Fracture, 1992, 54(3): 197-210.

[31] Y Takashima, M Ohata, K Inose, et al. Evaluation of Charpy impact toughness using side-grooved specimen for hybrid laser-arc welds of ultrahigh-strength steel. Welding in the World, 2016, 60(6): 1191-1199.

\section{Submit your manuscript to a SpringerOpen ${ }^{\odot}$ journal and benefit from:}

- Convenient online submission

- Rigorous peer review

- Open access: articles freely available online

- High visibility within the field

- Retaining the copyright to your article

Submit your next manuscript at $\boldsymbol{\nabla}$ springeropen.com 